\title{
A Critical Review of the Methods \\ Used to Estimate the Cost of An Adequate Education
}

\author{
R. Ramesh Rao (Corresponding author) \\ Faculty of Economics \& Administration \\ University Malaya \\ 50603 Kuala Lumpur, Malaysia \\ Tel: 60-17-879-2159Ｅ-mail: rameshdivan@yahoo.com \\ R. Sivabala Naidu \\ School of Humanities \\ Universiti Sains Malaysia \\ 11800 Minden, Penang, Malaysia \\ Tel: 60-12-482-4230Ｅ-mail: sivabala27@gmail.com \\ Rohana Jani \\ Department of Applied Statistics \\ Faculty of Economics \& Administration \\ University Malaya \\ 50603 Kuala Lumpur, Malaysia \\ Tel: 60-3-7967-3747Ｅ-mail: janir59@yahoo.com
}

\begin{abstract}
Policy and decision makers find the task of determining the cost of education a difficult process. One of the reasons for this is the complexity of the process itself. Answering questions such as: what entails an adequate education? and how much is needed to provide adequate education? is complex. Thus, stakeholders in the education sector need a thorough understanding of the concepts and knowledge of the variables that determine an adequate education. In relation to this, this paper seeks to provide an overview of the concepts and critically reviews various methods that are currently utilized to determine the cost of adequate education. It also makes comparisons between the methods and discusses the pros and cons in an objective and integrated manner.
\end{abstract}

\section{Introduction}

While, a bigger budget allocation can facilitate improvement in many areas in the educational sector, research has shown that there is really no distinct co-relation between the budget size and positive outcome in terms of student performance. In relation to this argument, it has been argued that a more important variable that determines educational outcomes is how the financial resources are managed and utilized. In other words, it is not the size of the budget allocation that is pertinent but rather how finance is managed in order to bring about the desired results. This brings into focus the following two concepts: 1) adequate (or adequacy) used in the phrase adequate education and 2) cost of adequate education which, hence, raises the oft-asked question: What is the least amount of money (considered adequate) that needs to be spent to achieve the desired level of educational outcome? (Andrews, Duncombe \& Yinger, 2002). In order to do this, one needs to thoroughly understand the concept of adequate in relation to one's own educational setting and the methods that can be used to calculate the cost of education. 
In relation to the scenario above, this paper, thus, attempts to provide a critical review of some of the more popular methods that are currently used to compute the cost of adequate education worldwide. Before this is done, it is important to establish the definitions of the key concepts in this paper.

\section{Definitions of the important concepts}

\subsection{Adequate}

In Myersk and Silverstein's definition (2002), the term adequate refers to the number of teachers required to perform a certain task or tasks using a specific type of resource. This is basically an "input-based" definition. Haveman (2004), in the contrary, defines the term from an "output-based" perspective: adequacy is said to have been achieved if certain test scores standards is achieved. From a broader perspective, such as a nation's desire to produce a knowledgeable workforce, adequacy is achieved when students achieve a set of specific skills as specified in the curriculum while studying in formal educational institutions. In most developing nations, the basic skills that a student is required to master are reading, writing, and mathematical skills. They should also have sufficient knowledge of the culture and heritage of their respective countries which will provide them with a sense of belonging and patriotism (see Reschovsky \& Imazeki, 1999).

\subsection{Cost of education}

According to Reschovsky and Imazeki, (1999), the phrase cost of education refers to the minimum amount of funding that is needed to produce the desired outcome. Basically, estimating the cost of education depends on the various related components of education. However, Hall (204) claims that a typical estimation of the cost of education often does not include certain components such as the cost involved in getting parents' support or contributions of cash or kind from private foundation. This means that any typical estimation of the cost of education is lower than the actual cost incurred.

While acknowledging the logic and relevance of Hall's view (2004), this paper prefers to utilize Reschovsky and Imazeki's (1999) definition as it would be tedious and cumbersome to actually obtain the data in such a specific manner. So, in this paper, cost of education is viewed as the minimum value of resources needed to produce the desired level of student output or the minimum amount of expenditure or outlay needed to produce a certain level of student achievement.

\section{Determining the Cost of adequate education}

There are numerous methods that are currently employed by researchers, education consultants and other relevant stakeholders to compute the cost of education. Each method has its own strengths and weaknesses. In the following sub-sections, a critical review of the major methods that are being used is provided.

\subsection{Professional Judgement Approach}

As the name suggests, the cost of education is basically determined by the teachers since they are the people who are directly involved with the students. Hence, researchers such as Fowler (1998) and Augenblick and Myers (2003) argue that teachers, more than any other stakeholders, would have a greater knowledge and skills to determine the quality and quantity of the various resources deemed necessary to ensure an adequate education.

The basic view that is posited by this approach is that it is the teachers, who are ideally-positioned in the education system; hence they will be able to describe in detail the kind of delivery systems that should be made available in educational institutions. This includes areas such as the counseling and technological resources that should be provided to meet the demands of students.

Given such a responsibility, the teachers would, thus, have the final say on the kind of resources and support services necessary to provide students with an adequate education. After the resources and services are identified, they are priced according to the existing market value which is computed as the cost of education in that particular setting (Verstegen, 2003). This method is quite popular in the education fraternity as it reflects the views of the actual service providers i.e. the teachers and easily implemented compared to other methods (Myers and Silverstein, 2002). However, many academics and researchers generally do not favor this method.

According to Duncombe and Lukemeyer (2002), the method is flawed because the cost is calculated based on the preferences of one segment of the education system without consideration of the views and opinions of the other stakeholders. Even that one segment is only made up of just a representative group made up of a few individuals and not every teacher.

Another criticism against this method is that the recommendations made by teachers are usually based on their current needs without much emphasis on the anticipated needs in the future (see, Verstegen, 2003; Augenblick and Myers, 2003; Myers and Silverstein, 2002). Thus, the dynamic and ever-evolving nature of the education system and technological advances are oft ignored. 
Studies have also shown that the teachers who are involved in calculating the cost of education rely entirely on their experience in making decision (Duncombe and Lukemeyer, 2002). In relation to this, the experience of the decision makers is multifaceted which often cause problems. For example, the experience of rural teachers may differ completely from those teaching in urban areas and decisions on the type of resources needed in schools will naturally differ. In addition, Verstegen (203) argues that the panel of decision-makers may rely on the element of guessing in their decision making process because their experience may be limited.

Researchers also believe that this method does not take into consideration the actual or projected achievement of students. For example, Peyser and Costrell's (2004) claim that there has been very little attempt to evaluate how the resources play a part in influencing student performance positively. In view of this, Verstgen (2003) argues that more research must be conducted to determine how the money spent on resources has a direct influence in terms of students' performance level.

Another pertinent criticism targeted towards this method is that it focuses more on the consumption of the resources rather than the actual expenditure incurred, thus, making the task of estimating the cost of an adequate education difficult (Odden, Archibald, Fermanich and Gross, 2002) Finally, it has been observed that teachers involved in the decision making process may overlook budget constraints and decide based on the notion that funds are unlimited, which is always not the case.

\subsection{Cost Function Approach}

This approach is considered better because cost function which allows decision makers to quantify the relationship between per-pupil spending for education, student performance, various student characteristics, and the economic and spatial characteristics of school districts are given due focus (Imazeki \& Reschovsky, 2004). This means that the influence of variables such as the setting of the school i.e. rural or urban, etc are given priority in computing the cost (Taylor and Keller, 2002). Similarly, Fowler (1998) states that researchers applying this method can include the differences in the price of resources across various locations. For example the price of educational resource, such as computers may not the same in every part of a country.

In this method, decision makers also take into account the patterns of input substitution that occur in response to differences in relative prices and differences in the technology requirements associated with pupil needs. For example, students in urban areas are likely to be more exposed to sophisticated technological advances than students from rural areas and may thus require more sophisticated hardware such as a scanner and so on.

Apart from the above-mentioned advantages, this method is also considered more superior as it not only considers the cost of resources but also the students' achievement in relation to the expenditure incurred. For example, achievement in an exam can be used as the yardstick to determine the cost of the adequacy.

There are several variables that researchers consider in determining the adequate cost of education via this approach. They are:

(i). District expenditure

(ii). Educational outcomes

(iii).School Size

(iv).Input prices such as teachers, administrators, Auxiliary personnel and Computer equipment \& Instructional equipment

(v). Environmental Factors such as range of students, and family and neighbourhood characteristics.

(vi).Capital

(vii).Geography or location of school

(viii).Efficiency of the school

(Gronberg, Jansen, Taylor \& Booker ,2004)

However, taking into consideration all the above variables alone does not ensure validity and reliability of the results, thus, it is equally important to determine the achievement standard and the acceptable (tolerable) level of inefficiency. This can be done if the cost index for each school is determined by dividing the predicted spending level for each district to the predicted spending level in a district with average characteristics.

\subsection{Empirical Identification Approach}

Another viable approach is the empirical identification approach, where the objectives are well laid and specified by the school or other stakeholders such as the district or state educational departments (Augenblick and Myers, 2003). In this method, schools that will serve as good models for research will be schools which have met the specified objectives. Usually, a minimum level of test achievements is used as the yardstick (Duncombe and Lukemeyer 2002). Basically, this approach utilizes a 3 -step procedure as listed in the table below: 


\begin{tabular}{|l|l|}
\hline Step 1 & A set of schools are selected which have met the state standards. \\
\hline Step 2 & The total expenditure of the school is utilized to calculate the cost \\
\hline Step 3 & A base cost figure using the basic expenditure figure is calculated \\
\hline
\end{tabular}

Source: Augenblick and Myers (2003)

This method has two main advantages. According to Harris (2004) and Verstegen (2003) this approach is objective as it enables non-school factors like family background to be included in determining the cost. Secondly, since this method is based on actual evidence, it therefore does not require further testing.

The main weakness, however, is that schools which have outcomes or achievement beyond the norm are omitted. Thus, Verstegen (2003) questions the validity of this approach because it does not include these 'outliers' school in the process of computing the cost. In addition, Peyser and Costrell (2004) have questioned the practicality of this approach as they believe that it would be time-consuming to include the data of every student in the education system. Another weakness of this method is that the exact breakdown on how the selected schools have spent their money is often left out; instead only the average basic expenditure is provided (Augenblick and Myers, 2003).

\subsection{Whole School Design Method}

In this approach, a few schools are selected randomly to participate in an educational program. At the end of the program, the outcome of the program is evaluated. The best performing school in the program is then selected to serve as a benchmark for the other schools to follow in the future.

The main criticism of this approach is that the schools selected are selected randomly and thus, may not be a proper representation of the particular setting. In addition, there is also a tendency to eliminate the highest and lowest spending schools from the analysis in this method as noted by Odden, (2003) who claims that schools from large districts and urban schools are often not selected to take part in the program, thus raising doubts on its validity.

\section{Conclusion}

Determining what is adequate for the students and its cost is an important process. Hence, it is not surprising that there are several ways to compute the cost of an adequate education. Each method has its strengths and drawbacks. Thus, it is vital that a concerted effort is taken to select the most practical method, in relation to the local conditions. If the situation permits, it would be ideal to estimate the cost in a more localized basis such as within particular districts as the cost of adequate education will definitely differ according to the location. Another possibility is to use more than one method to increase the validity and reliability of the findings. However, the question to be answered is: Are these suggestions practical in real-world situations?

Decision makers must also note that there is little evidence to directly link more funds to better student achievement and performance. The crucial factor is the effective and efficient management of these funds. This means that it is vital for all stakeholders to take the necessary steps to ensure proper management of funds to maximize the benefits.

\section{References}

Andrews, M., Duncombe, W., \& Yinger, J. (2002). Revisiting economies of size in American education: are we any closer to a consensus? Economics of Education Review, 21, 245-262.

Augenblick, \& Myers. (2003, January ). Calculation of the cost of an adequate education in Colorado using the Professional Judgement and the Successful District Approach. Retrieved 26 August, 2006, from http://www.cosfp.org/pdfs/FULLREPO.PDF

Chambers, J. G., Parrish, T. B., Smith, J. R., \& Guthrie, J. W. (2004). The New York Adequacy Study: "Adequate" Education Cost in New York State: Project Preliminary Report: American Institute For Research \& Management Analysis and Planning Inc.

Downes, T. (2004, February). What is Adequate? Operationalizing the Concept of Adequacy for New York. Paper presented at the EFRC Symposium on School Finance and Organizational Structure in New York State, New York.

Duncombe, W., \& Lukemeyer, A. (2002, March). Estimating the cost of Educational Adequacy: A comparison of Approaches. Paper presented at the Annual Conference of the American Education Finance Association.

Gronberg, T. J., Jansen, D. W., Taylor, L. L., \& Booker, K. (2004). School Outcomes and School Costs: The Cost Function Approach. Texas. USA: Texas Joint Select Committee on Public School Finance, Austin.

Hall, T. (2004). Public Education as a Business: Real Costs and Accountability. NASSP Bulletin, 88(640), 84-86.

Harris, D. N. (2004, April). Funding Florida's Schools: Adequacy, Cost and the State Constitution. from http://www.asu.edu/educ/epsl/EPRU/documents/EPSL-0401-110-EPRU.pdf 
Haveman, M. (2004). Determining the Cost of an Adequate Education in Minnesota: Implications for the Minnesota Education Finance System. Retrieved 19 February, 2007, from http://www.mntax.org/cpfr/education.pdf

Imazeki, J., \& Reschovsky, A. (2004, June). Is No Child Left Behind an Un (or under) funded Federal Mandate? Evidence from Texas. Retrieved 28 November, 2006, from http://www.lafollette-wisc.edu/publications/otherpubllications/education/2004/Reschovsky-NCLB-Unfunded.pdf

Myers, J., \& Silverstein, J. (2002, August). Calculation of the cost of a suitable education in Montana in 2001-2002 using the Professional Judgement Approach. 2007, from http://wwwmtsba.org/study/Final\%20Report.pdf

Odden, A. (2003). Equity and Adequacy in School Finance Today. Retrieved 30 April, 2008, from http://www.edsourceonline.com/pdf/sfequityadequacy.pdf

Odden, A., Archibald, S., Fermanich, M., \& Gross, B. (2003). Defining School-level Expenditure Structures that Reflect Educational Strategies. The Journal of Education Finance, 28(3), 323-356.

Peyser, J., \& Costrell, R. (2004). Exploring the Cost Accountability [Electronic Version], 13. Retrieved 18 November 2007 from http://www.hks.harvard.edu/pepg/PDF/Papers/Peyser_Costrell.pdf.

Reschovsky, A., \& Imazeki, J. (1999). Does the School Finance System in Texas Provide Students with an Adequate Education? Paper presented at the Conference Name|. Retrieved Access Date|. from URL|.

Taylor, L. L., \& Keller, H. (2002). Competing Perspectives on the cost of Education. Development in School Finance: 2001-02 Retrieved 25 March, 2008, from http://nces.ed.gov/edfin/pdf/comp_pers_2003403.pdf

Verstegen, D. A. (2003). Calculation of the cost of an adequate education in Kentucky. Retrieved 26 March, 2008, from http://www.schoolfunding.info/states/ky/KYAdequacyStudy.pdf 